\title{
Prediction of Type 2 Diabetes Remission after Bariatric or Metabolic Surgery
}

\author{
Ji Yeon Park* \\ Department of Surgery, School of Medicine, Kyungpook National University, Kyungpook National University Chilgok Hospital, Daegu, Korea
}

Bariatric surgery has evolved from a surgical measure for treating morbid obesity to an epochal remedy for treating metabolic syndrome as a whole, which is represented by type 2 diabetes mellitus. Numerous clinical trials have advocated bariatric or metabolic surgery over nonsurgical interventions because of markedly superior metabolic outcomes in morbidly obese patients who satisfy traditional criteria for bariatric surgery (body mass index $[\mathrm{BMl}]>35 \mathrm{~kg} / \mathrm{m}^{2}$ ) and in less obese or simply overweight patients. Nevertheless, not all diabetes patients achieve the most desirable outcomes; i.e., diabetes remission after metabolic surgery. Thus, candidates for metabolic surgery should be carefully selected based on comprehensive preoperative assessments of the risk-benefit ratio. Predictors for diabetes remission after metabolic surgery may be classified into two groups based on mechanism of action. The first is indices for preserved pancreatic beta-cell function, including younger age, shorter duration of diabetes, and higher C-peptide level. The second is the potential for an insulin resistance reduction, including higher baseline BMI and visceral fat area. Several prediction models for diabetes remission have been suggested by merging these two to guide the joint decision-making process between clinicians and patients. Three such models, DiaRem, $A B C D$, and individualized metabolic surgery scores, provide an intuitive scoring system and have been validated in an independent external cohort and can be utilized in routine clinical practice. These prediction models need further validation in various ethnicities to ensure universal applicability.

Key words: Bariatric surgery, Diabetes mellitus, Morbid obesity, Metabolic syndrome, Weight loss

\author{
Received October 20, 2018 \\ Reviewed November 15, 2018 \\ Accepted November 19, 2018 \\ *Corresponding author \\ Ji Yeon Park \\ (i) \\ https://orcid.org/0000-0002-6178-7906 \\ Department of Surgery, School of \\ Medicine, Kyungpook National \\ University, Kyungpook National \\ University Chilgok Hospital, \\ 807 Hoguk-ro, Buk-gu, Daegu 41404, \\ Korea \\ Tel: +82-53-200-2711 \\ Fax: +82-53-200-2027 \\ E-mail: jybark99@hanmail.net
}

\section{INTRODUCTION}

Type 2 diabetes mellitus (T2DM) is an increasing pandemic affecting >400 million people worldwide. ${ }^{1}$ Unfortunately, approximately one third of these diabetes patients live in the Asia-Pacific area. The risk of developing T2DM is greater for obese Asians than for Caucasians with the same body mass index (BMI) because of the higher proportion of body fat and prominent abdominal obesity. ${ }^{2,3}$

T2DM prevalence is also increasing in Korea, from 8.6\% in 2001 to $11.0 \%$ in 2013 among adults aged $\geq 30$ years, according to the Korea National Health and Nutrition Examination Surveys. ${ }^{4}$ Despite the rapidly increasing diversity of pharmaceutical options, the control of diabetes over the last decade in Korea has been minimal.
According to the Korean National Survey, which included 1,341 patients with diabetes aged $>30$ years, only $27 \%$ of patients with diabetes met the well-controlled diabetes glycosylated hemoglobin (HbAlc) level $<6.5 \%$ and only $45.6 \%$ achieved an $\mathrm{HbAlc}<7 \%$ in 2012; these values demonstrate the little change made since 2005 and indicate that a breakthrough in the fight against this chronic disease is needed. ${ }^{5}$

The efficacy of bariatric surgery on remarkable and sustained weight loss has been well demonstrated in numerous studies ${ }^{6-9}$, and it is no longer disputable that surgical measures induce distinctly superior outcomes in terms of weight loss compared to any other medical treatments. Along with sustained weight loss, bariatric surgery achieves a marked improvement in obesity-related comorbidi- 
ties, including T2DM. Since Dr. Pories introduced metabolic surgery in 1995, suggesting surgical treatments as a potential cure for diabetes ${ }^{10}$, several studies have focused on the metabolic effect of bariatric surgery. ${ }^{8,11-13}$ This trend shifted the paradigm from bariatric surgery, which was aimed at body weight reduction, toward "metabolic surgery," which primarily intends to treat metabolic diseases, particularly T2DM. Based on extensive evidence, the international diabetes organization, encompassing over 50 medical and surgical societies, released a joint statement in 2016 endorsing metabolic surgery for uncontrolled T2DM patients despite optimal medical management, even for those with class I obesity (BMI, $27.5-32.5 \mathrm{~kg} / \mathrm{m}^{2}$ for Asians). ${ }^{14}$ This indirectly reflects that a consensus has been reached that improvement in diabetes mellitus after bariatric surgery is related to mechanisms other than simple weight loss alone, although they are not completely understood yet. $^{15}$

Nevertheless, not all diabetes patients achieve the desirable outcome of diabetes remission after surgical treatment. Surgery may also pose nutritional risks requiring long-term monitoring and supplementation in patients. Candidates for metabolic surgery should be selected carefully based on a comprehensive preoperative assessment of the risk-benefit ratio. Although many studies show that baseline BMI does not adequately predict metabolic surgery outcomes $^{16}$, the most current evidence is based on studies using the conventional eligibility criteria of BMI $>35 \mathrm{~kg} / \mathrm{m}^{2}$ for bariatric surgery. Selecting patients based on BMI criteria is currently inevitable. However, investigators have argued that more robust diabetesspecific parameters, besides BMI, should be established to identify suitable patients for metabolic surgery and predict postoperative outcomes.

\section{DEFINITION OF DIABETES REMISSION}

There has been great heterogeneity in defining diabetes remission in the literature. The rate of diabetes remission following bariatric and metabolic surgery can be largely affected by how remission is defined. Mas-Lorenzo et al. ${ }^{17}$ revealed that the remission rate decreased from $92.7 \%$ to $43.6 \%$ with a more stringent definition of remission in a diabetes patient cohort $(\mathrm{n}=55)$ undergoing a Roux-en-Y gastric bypass (RYGB) or sleeve gastrectomy (SG).
Blackstone et al. $^{18}$ reviewed 505 patients who underwent RYGB and demonstrated that the diabetes remission prevalence at 14 postoperative months varied from $43.2 \%$ to $59.4 \%$ depending on the definition of remission. They concluded that the independent predictors for remission were consistent regardless of how remission was defined.

So far, the most commonly used definition for remission is based on a 2009 consensus statement by a panel of expert endocrinologists. ${ }^{19}$ They defined remission as achieving glycemia below the diabetes range in the absence of active pharmacological or surgical therapy. Partial remission was defined as subdiabetic hyperglycemia (HbAlc $<6.5 \%$ and fasting glucose $100-125 \mathrm{mg} / \mathrm{dL}$ ) for at least 1 year, and complete remission is a complete return to normal glucose metabolism measurements (normal HbAlc and fasting glucose $<100 \mathrm{mg} / \mathrm{dL}$ ) for the same duration. Prolonged remission was considered complete remission lasting for $>5$ years.

However, this rather strict definition has not been uniformly adopted in studies, even after the statement was publicly released. Most studies have used an $\mathrm{HbAlc}$ measurement at a single time point during the follow-up to define diabetes remission without considering sustained remission status for a given period of time. ${ }^{18,20-24}$ One reason for this may be that researchers are inclined to release the best possible outcomes. This strict definition with the additional time frame seemingly renders metabolic surgery less effective than initially expected. In previous studies, the stricter the criteria, the lower the remission rate within the same study cohort. ${ }^{17}$ Furthermore, according to this definition, patients who keep taking preventive medication after surgery, including metformin, are not regarded to have attained diabetes remission despite excellent glycemic control after surgery because those patients did not discontinue oral hypoglycemic agents. Clarifying standard criteria for diabetes remission for use in clinical practice, as well as scientifically is important to compare objective evidence across various studies.

\section{PROBABILITIES OF DIABETES REMISSION}

The efficacy of bariatric or metabolic surgery on T2DM in morbidly obese patients has been extensively studied. The Swedish Obese Subject study prospectively observed 343 and 260 diabetes 
patients in a bariatric surgery group and matched control group, respectively. ${ }^{25}$ The study followed up patients for $12-25$ years. Surgical procedures used were gastric bypass, gastric banding, and vertical banded gastroplasty. The diabetes remission rates were $72.3 \%$ and $16.4 \%$ in the surgery and control groups, respectively, at 2 years after surgery. At 15 years, the diabetes remission rate decreased to $30.4 \%$ and $6.5 \%$ for surgical patients and controls, respectively. Thus, bariatric surgery was associated with more frequent diabetes remission and significantly reduced diabetes-related complications in obese T2DM patients although some patients experienced diabetes relapse over time. ${ }^{25}$

According to a previous meta-analysis published in 2009 involving 3,188 diabetes patients, Buchwald et al. ${ }^{6}$ reported an overall complete diabetes remission rate of $78.1 \%$ after bariatric surgery, achieving normal fasting blood glucose levels $(<100 \mathrm{mg} / \mathrm{dL})$ or $\mathrm{HbAlc}<6 \%$ without diabetes medications. Diabetes resolution was the greatest for patients undergoing biliopancreatic diversion/ duodenal switch (95.1\%), followed by gastric bypass (80.3\%); gastroplasty (79.7\%), which has been discarded in recent years; and gastric banding (56.7\%). This gradient significantly correlated to BMI loss achieved following the different bariatric procedures.

A recent meta-analysis in the United Kingdom involved 569 T2DM patients with $\mathrm{BMI}>35 \mathrm{~kg} / \mathrm{m}^{2}$ who underwent bariatric surgery and matched them to 1,881 diabetes patients without bariatric surgery for age, sex, and baseline BMI. A rate of 94.5 diabetes remissions per 1,000 person-years was observed in patients who underwent bariatric surgery compared with 4.9 diabetes remissions in matched control patients. Patients who underwent bariatric surgery had an 18-fold increased chance for diabetes remission compared with matched controls. ${ }^{26}$ Consistent with other studies, the effect size was the greatest for patients undergoing gastric bypass (adjusted relative rate $[R R], 43.1$ ), followed by SG (adjusted RR, 16.6) and gastric banding (adjusted RR, 6.9).

Surgical procedures inducing malabsorption appear to have a better antidiabetic effect compared to purely restrictive procedures, including gastric banding or SG, in morbidly obese patients, along with better weight loss outcomes. The question is if metabolic surgery would work for diabetes patients with much lower BMI. Many researchers have argued that the antidiabetic effect of metabolic surgery is owing to weight loss-related changes in the glucose ho- meostasis and diverse weight loss-independent mechanisms of glycemic control. Although not completely understood, these include favorable changes in gut hormones, bile acid signaling, intestinal nutrient sensing, gut microbiota, and increased glucose metabolism in the small intestine. ${ }^{15}$ However, most of these specific mechanisms have only been demonstrated in animals thus far, and evidence in humans is lacking and under present investigation.

The evidence supporting the efficacy of metabolic surgery for those with BMI $<35 \mathrm{~kg} / \mathrm{m}^{2}$ is limited. Several studies, albeit with relatively small sample sizes, have investigated the efficacy of metabolic surgery in nonmorbidly obese diabetes patients with BMI $<35 \mathrm{~kg} / \mathrm{m}^{2}$. One thing to note is the majority of these studies employed procedures that were not purely restrictive, including intestinal bypass.

Rao et al. ${ }^{27}$ conducted a meta-analysis, including 269 participants from nine articles, to investigate the effect of gastric bypass (including both traditional RYGB and mini-gastric bypass) on T2DM in patients with $\mathrm{BMI}<35 \mathrm{~kg} / \mathrm{m}^{2}$ for a minimum 12-month follow-up period. The mean BMI decreased from $31.0 \pm 2.1$ to $25.3 \pm 3.4 \mathrm{~kg} / \mathrm{m}^{2}$ and the $\mathrm{HbAlc}$ level from $8.3 \% \pm 1.8 \%$ to $5.8 \% \pm 0.8 \%$. The overall diabetes remission rate was $57 \%$ (range, 23\%-93\%).

Baskota et al. ${ }^{28}$ evaluated results of patients with BMI $<30 \mathrm{~kg} / \mathrm{m}^{2}$ in a meta-analysis including 291 diabetes patients from 10 studies. Most were preliminary studies with very small sample sizes $(<30$ patients), short follow-up periods, and more than a half of the patients were from the Asia-Pacific region. Pooled results demonstrated a weight loss of $9.7 \mathrm{~kg}$ and a diabetes remission rate of $42.4 \%$. A study by Dixon et al. ${ }^{29}$ is one of the largest thus far, which reported the outcomes of gastric bypass (RYGB or mini-gastric bypass) in 103 diabetes patients with $\mathrm{BMI}<30 \mathrm{~kg} / \mathrm{m}^{2}$ (mean \pm standard deviation, $25.9 \pm 3.0 \mathrm{~kg} / \mathrm{m}^{2}$ ). Participants were either Korean or Taiwanese. Excellent glycemic control with an $\mathrm{HbAlc}<6.0 \%$ was achieved in only $30 \%$ of patients at 1 -year postsurgery, which is considerably lower than figures in studies based on a higher BMI population. The surgical efficacy on diabetes resolution seems less prominent in the less or nonobese patients compared to morbidly obese patients.

Panunzi et al. ${ }^{16}$ conducted a meta-analyses with 94 previously published studies that comprised 4,944 T2DM patients. They categorized the patients into two subgroups based on their preopera- 
tive BMI $\left(\mathrm{BMI}<35\right.$ or $\left.>35 \mathrm{~kg} / \mathrm{m}^{2}\right)$ to compare the surgical effect on T2DM. The rate of diabetes remission was similar between the two subgroups at $71 \%$ and $72 \%$, respectively. They concluded that preoperative BMI does not predict the postoperative outcome of T2DM.

\section{PREDICTIVE FACTORS OF DIABETES REMISSION FOLLOWING BARIATRIC OR METABOLIC SURGERY}

Several studies have investigated outcomes of bariatric surgery in patients with T2DM to identify predictive factors of diabetes remission following surgery (Table 1)..$^{7,13,18,20-24,30}$ The remission rate ranged from $24 \%$ to $84 \%$ according to the type of surgery and the baseline characteristics of the patients. As shown in Table 1, these studies were heterogeneous in terms of sample size, follow-up duration, and definition of remission used.

Interestingly, some factors emerged as common denominators of diabetes remission across these studies despite different surgical types and remission criteria. These included a younger age, higher baseline BMI, shorter duration of diabetes, and better glycemic control before surgery, which may be represented by a lower $\mathrm{HbA1c}$ or fasting plasma glucose and no preoperative insulin use (Table 1). Some studies suggested that a lower baseline C-peptide level was associated with poor control of diabetes after bariatric surgery. ${ }^{20}$ A study of Korean patients demonstrated similar results as those of other studies, including that a baseline C-peptide level $>2.6 \mathrm{ng} / \mathrm{mL}$ was a prerequisite for diabetes remission and that preoperative BMI, younger age, and a lower $\mathrm{HbAlc}$ with no insulin use before the surgery independently predicted diabetes remission

Table 1. Predictors of diabetes remission after bariatric or metabolic surgery

\begin{tabular}{|c|c|c|c|c|c|c|c|c|}
\hline Author (year) & Number & Type of surgery & $\begin{array}{l}\text { Baseline BMl } \\
\left(\mathrm{kg} / \mathrm{m}^{2}\right)\end{array}$ & $\begin{array}{c}\text { Baseline } \mathrm{HbA} 1 \mathrm{c} \\
(\%)\end{array}$ & $\begin{array}{l}\text { Duration of } \\
\text { diabetes (yr) }\end{array}$ & Remission rate & $\begin{array}{c}\text { Definition of } \\
\text { diabetes remission }\end{array}$ & Predictor of diabetes remission \\
\hline $\begin{array}{l}\text { Hayes et al. } \\
(2011)^{23}\end{array}$ & 127 & RYGB & $46.8 \pm 9.4$ & $7.7 \pm 1.7$ & $4.5 \pm 5$ & $\begin{array}{c}84 \% \text { at } 12 \\
\text { months }\end{array}$ & $\begin{array}{l}\mathrm{HbA} 1 \mathrm{c}<6 \% \text { without } \\
\text { medication }\end{array}$ & $\begin{array}{l}\text { Preoperative BMI, HbA1c, FPG } \\
\text { presence of hypertension } \\
\text { T2DM status }\end{array}$ \\
\hline $\begin{array}{l}\text { Hamza et al. } \\
(2011)^{22}\end{array}$ & 74 & LAGB \& RYGB & $51.6 \pm 8.2$ & $\begin{array}{l}\text { LAGB, } 7.5 \pm 1.8 \\
\text { RYGB, } 7.9 \pm 1.9\end{array}$ & $\begin{array}{l}<5(n=34) \\
\geq 5(n=30)\end{array}$ & $\begin{array}{l}\text { LAGB, 24\%; } \\
\text { RYGB, 50\% at } \\
17 \text { months }\end{array}$ & $\begin{array}{l}\mathrm{HbA} 1 \mathrm{c}<6.5 \% \text { \& FPG } \\
\quad<100 \text { without } \\
\text { medication }\end{array}$ & $\begin{array}{l}\text { Age, \%EWL (type of surgery, female, } \\
\text { follow-up duration) }\end{array}$ \\
\hline $\begin{array}{l}\text { Blackstone } \\
\text { et al. }(2012)^{18}\end{array}$ & 505 & RYGB & $48.7 \pm 8.1$ & $7.5 \pm 1.6$ & Median, 4 & $\begin{array}{l}43.2 \% \text { at } 14 \\
\text { months }\end{array}$ & $\begin{array}{l}\mathrm{HbA} 1 \mathrm{c}<5.7 \% \text { \& FPG } \\
\quad<100 \text { without } \\
\text { medication }\end{array}$ & $\begin{array}{l}\text { Preoperative FPG, HbA1c } \\
\text { Preoperative insulin use } \\
\text { Duration of T2DM }<4 \text { years }\end{array}$ \\
\hline $\begin{array}{l}\text { Aarts et al. } \\
\qquad(2013)^{20}\end{array}$ & 56 & RYGB & $48.1 \pm 6.3$ & $7.4 \pm 1.5$ & $\begin{array}{l}\mathrm{OHA}, 4.8 \pm 5.0 \\
\text { insulin, } 8.7 \pm 6.1\end{array}$ & $74 \%$ & $\begin{array}{l}\mathrm{HbA1c} \leq 6.5 \% \text { without } \\
\text { medication }\end{array}$ & $\begin{array}{l}\text { Recent T2DM diagnosis } \\
\text { Lower preoperative HbA1c } \\
\text { Lower daily doses of metformin } \\
\text { Lower daily doses of insulin }\end{array}$ \\
\hline $\begin{array}{l}\text { Schauer et al. } \\
(2014)^{13}\end{array}$ & 99 & RYGB \& LSG & $36 \pm 3.5$ & $9.3 \pm 1.5$ & $8.3 \pm 5.1$ & $\begin{array}{l}\text { RYGB, } 46 \% \text {; } \\
\text { LSG, 29\% at } \\
3 \text { years }\end{array}$ & $\begin{array}{l}\mathrm{HbA1c}<6.5 \% \text { without } \\
\text { medication }\end{array}$ & $\begin{array}{l}\text { Reduction in BMI }(O R, 1.33) \\
\text { Duration of T2DM < } 8 \text { years }(O R, 3.3)\end{array}$ \\
\hline $\begin{array}{l}\text { Bhasker et al. } \\
(2015)^{21}\end{array}$ & 106 & RYGB & $45 \pm 7.8$ & $8.7 \pm 2.1$ & $8.2 \pm 6.2$ & $\begin{array}{l}\mathrm{NA}(\mathrm{HbA} 1 \mathrm{c} \\
6.2 \pm 1.3 \text { at } \\
5 \text { years })\end{array}$ & $\begin{array}{l}\mathrm{HbA1 \textrm {C }}<6 \% \text { \& FPG } \\
<100 \text { without } \\
\text { medication for } 6 \\
\text { months }\end{array}$ & $\begin{array}{l}\text { C-peptide levels } \geq 3 \mathrm{ng} / \mathrm{mL} \\
\text { Duration of T2DM } \leq 5 \text { years } \\
\text { BMI } \geq 40 \mathrm{~kg} / \mathrm{m}^{2} \\
\text { No preoperative insulin use }\end{array}$ \\
\hline $\begin{array}{l}\text { Yu et al. } \\
(2015)^{30}\end{array}$ & 68 & RYGB & $31.5 \pm 3.6$ & $8.6 \pm 2.1$ & 7 & $73.5 \%$ at 1 year & $\begin{array}{l}\mathrm{HbA1c}<6.5 \% \text { without } \\
\text { medication }\end{array}$ & $\begin{array}{l}\text { Shorter T2DM duration } \\
\text { C-peptide } \\
\text { VFA }\end{array}$ \\
\hline $\begin{array}{l}\text { Park and Kim } \\
(2016)^{24}\end{array}$ & 134 & RYGB & $37.9 \pm 5.2$ & $8.0 \pm 1.5$ & $4.6 \pm 5.8$ & $\begin{array}{l}46.1 \% \text { at } 12 \\
\text { months }\end{array}$ & $\begin{array}{l}\mathrm{HbA} 1 \mathrm{c}<6 \% \text { without } \\
\text { medication }\end{array}$ & $\begin{array}{l}\text { C-peptide levels }>2.6 \mathrm{ng} / \mathrm{mL} \\
\text { Age } \\
\text { Preoperative BMI, HbA1C, insulin use }\end{array}$ \\
\hline $\begin{array}{l}\text { Scopinaro } \\
\text { et al. }(2017)^{7}\end{array}$ & 135 & BPD & $27.0 \pm 9.6$ & $9.2 \pm 1.7$ & $11.1 \pm 7.8$ & $60.7 \%$ at 5 years & $\begin{array}{l}\mathrm{HbA} 1 \mathrm{c}<6.5 \% \text { without } \\
\text { medication }\end{array}$ & $\begin{array}{l}\text { Preoperative BMI } \\
\text { Preoperative insulin use }\end{array}$ \\
\hline
\end{tabular}

Values are presented as mean \pm standard deviation.

BMI, body mass index; HbA1c, glycosylated hemoglobin; RYGB, Roux-en-Y gastric bypass; FPG, fasting plasma glucose; T2DM, type 2 diabetes mellitus; LAGB, laparoscopic adjustable gastric banding; EWL, excess weight loss; OHA, oral hypoglycemic agents; LSG, laparoscopic sleeve gastrectomy; OR, odds ratio; NA, not available; VFA, visceral fat area; BPD, biliopancreatic diversion. 
among those who underwent RYGB. ${ }^{24}$

These previously proposed predictors can be classified into two subgroups. One group shows the preserved or less deteriorated ability of pancreatic beta-cell function to secrete insulin after glucose challenge, including a higher preoperative C-peptide level, shorter duration of diabetes, younger age, and good glycemic control without insulin use. The other group shows the potential for a reduction in insulin resistance. This can be indirectly represented by a higher preoperative BMI, higher visceral fat area, and a larger amount of weight loss following the surgery.

\section{PREDICTION MODELS OF DIABETES REMISSION}

Most of the previously published studies have focused on identifying factors to predict postoperative diabetes remission and results were based the retrospective analyses of data retrieved from a single-center cohort of a relatively small population. Recently, three prediction models of diabetes remission have been introduced that could serve as more intuitive and practical for use in clinical practice. They were assembled from a relatively large number of patients and were externally validated to verify their general applicability in other populations.

\section{DiaRem score}

DiaRem Score was proposed by Still et al. ${ }^{31}$ based on a retrospective review of 690 patients with T2DM who underwent RYGB. They reported a complete or partial remission rate of $63 \%$. They used 259 clinical variables to identify independent predictive factors and to develop a prediction model. They found that patients who required insulin for glycemic control before surgery were 7.25 times less likely to achieve either complete or partial remission after surgery, which was the strongest indicator to predict diabetes remission after bariatric or metabolic surgery. Additionally, age at operation, baseline $\mathrm{HbAlc}$ level, and type of antidiabetic medications used before surgery appeared to be predictors irrespective of insulin use. Based on these result, a scoring system ranging from 0 to 22 was established by weighing each variable based on the probability of diabetes remission (Table 2). Scores were classified into five groups according to the probability of diabetes remission, and a
Table 2. Calculation of DiaRem score and probability of diabetes remission after Roux-en-Y gastric bypass

\begin{tabular}{lc}
\hline Variable & Score \\
\hline Age (yr) & \\
$<40$ & 0 \\
$40-49$ & 1 \\
$50-59$ & 2 \\
$\geq 60$ & 3 \\
HbA1c (\%) & \\
$<6.5$ & 0 \\
$6.5-6.9$ & 2 \\
$7.0-8.9$ & 4 \\
$\geq 9.0$ & 6 \\
Other diabetes drugs & \\
No sulfonylureas or insulin-sensitizing agents other than metformin & 0 \\
Sulfonylureas and insulin-sensitizing agents other than metformin & 3 \\
Treatment with insulin & \\
No & \\
Yes & \\
Overall score (sum of the four components) & 10 \\
Probability of remission in each DiaRem score subgroup* & $0-22$ \\
$0-2$ & $87(83-90)$ \\
$3-7$ & 66 (61-70) \\
$8-12$ & $32(24-40)$ \\
$13-17$ & $16(12-21)$ \\
$18-22$ & $5(0-9)$ \\
\hline
\end{tabular}

Values are presented as probability (\%) with 95\% confidence interval.

*Including both partial and complete remissions.

$\mathrm{HbA1c}$, glycosylated hemoglobin.

Adapted from Still CD, et al. Lancet Diabetes Endocrinol 2014;2:38-45, with permission from Elsevier. ${ }^{31}$

higher score indicated a higher probability of remission. This scoring system was externally validated in an independent population and in several subsequent studies..$^{32,33}$

\section{$\mathrm{ABCD}$ score}

$\mathrm{ABCD}$ score was devised by Wei-Jei Lee and other representative bariatric surgeons from Asia. ${ }^{34}$ They initially reviewed 63 patients who underwent RYGB or single-anastomosis gastric bypass (previously known as mini-gastric bypass) and identified four factors, including age at operation (A), baseline BMI (B), C-peptide level (C), and diabetes duration (D). These factors were used to construct a simple scaling system ranging from 0 to 10 . Patients with a higher score are more likely to achieve diabetes remission after surgery. This original scoring system went through some modifications to enhance the predictive power with very low scores, particularly re- 
Table 3. Modified ABCD scoring system and the probability of diabetes remission after gastric bypass

\begin{tabular}{|c|c|c|c|c|}
\hline \multirow{2}{*}{ Variable } & \multicolumn{4}{|c|}{ Point on ABCD index } \\
\hline & 0 & 1 & 2 & 3 \\
\hline Age (yr) & $\geq 40$ & $<40$ & & \\
\hline BMI $\left(\mathrm{kg} / \mathrm{m}^{2}\right)$ & $<27.0$ & $27.0-34.9$ & $35.0-41.9$ & $\geq 42.0$ \\
\hline C-peptide (mg/L) & $<2.0$ & $2.0-2.9$ & $3.0-4.9$ & $\geq 5.0$ \\
\hline Duration of diabetes (yr) & $>8$ & $4-8$ & $1-3.9$ & $<1$ \\
\hline \multirow{2}{*}{$\mathrm{ABCD}$ score $(\%)$} & \multicolumn{4}{|c|}{ Probability of diabetes remission* } \\
\hline & \multicolumn{2}{|c|}{ Complete remission } & \multicolumn{2}{|c|}{ Partial remission } \\
\hline 0 & \multicolumn{2}{|c|}{5.9} & \multicolumn{2}{|c|}{5.9} \\
\hline 1 & \multicolumn{2}{|c|}{5.0} & \multicolumn{2}{|c|}{20.0} \\
\hline 2 & \multicolumn{2}{|c|}{26.3} & \multicolumn{2}{|c|}{38.6} \\
\hline 3 & \multicolumn{2}{|c|}{31.9} & \multicolumn{2}{|c|}{42.0} \\
\hline 4 & \multicolumn{2}{|c|}{52.5} & \multicolumn{2}{|c|}{67.8} \\
\hline 5 & \multicolumn{2}{|c|}{55.4} & \multicolumn{2}{|c|}{75.0} \\
\hline 6 & \multicolumn{2}{|c|}{61.7} & \multicolumn{2}{|c|}{78.3} \\
\hline 7 & \multicolumn{2}{|c|}{77.0} & \multicolumn{2}{|c|}{92.3} \\
\hline 8 & \multicolumn{2}{|c|}{85.2} & \multicolumn{2}{|c|}{96.3} \\
\hline 9 & \multicolumn{2}{|c|}{87.1} & \multicolumn{2}{|c|}{87.1} \\
\hline 10 & \multicolumn{2}{|c|}{93.9} & \multicolumn{2}{|c|}{93.3} \\
\hline Overall & \multicolumn{2}{|c|}{52.2} & \multicolumn{2}{|c|}{64.7} \\
\hline
\end{tabular}

${ }^{*}$ According to the analysis of 510 patients of Asian Diabetes Surgery Study. $\mathrm{BMI}$, body mass index.

Adapted from Lee WJ, et al. Obes Surg 2015;25:1772-8, with permission from Springer Nature. $^{35}$ flecting results from the lower BMI population (Table 3). ${ }^{35}$ The modified $\mathrm{ABCD}$ scoring system has been tested in 510 patients from different hospitals across Asia and demonstrated very good predictability of diabetes remission from 5.9\% to $93.3 \%$ along with increase in score. ${ }^{36}$ The system was also tested in SG patients and showed good correlation with the diabetes mission rate as well although with lower remission rates compared to gastric bypass patients in the original cohort. ${ }^{37}$ This indicates that the type of surgery has a significant influence on glycemic control after metabolic surgery.

\section{Individualized metabolic surgery score}

Aminian et al. ${ }^{38}$ devised the individualized metabolic surgery (IMS) scoring system to guide procedure selection based on longterm ( $>5$ years) glucose control in patients with T2DM. They retrospectively collected data from $659 \mathrm{~T} 2 \mathrm{DM}$ patients who underwent RYGB or SG at a single center in the United States and had completely documented glycemic follow-up for at least 5 years after surgery. A nomogram was constructed to generate the IMS score based on four independent predictors of long-term remission, which included preoperative number of diabetes medications, in-
Points

Preop number of diabetes medications

Preop insulin use

Preop duration of diabetes (year)

Preop glycemic control $(\mathrm{HbA} 1 \mathrm{c}<7 \%)$

Total points: Individualized metabolic surgery score
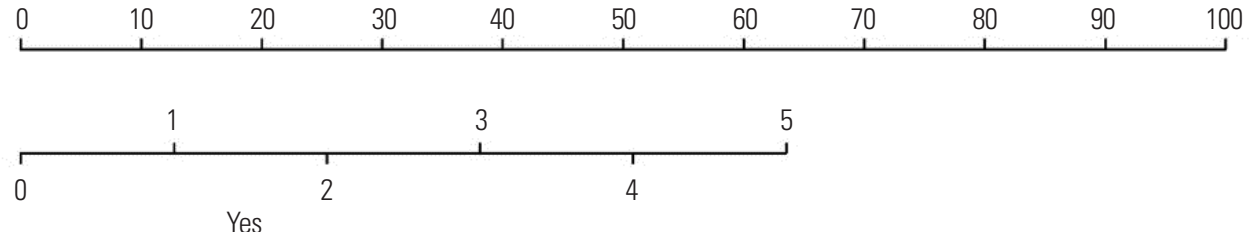

Yes

No

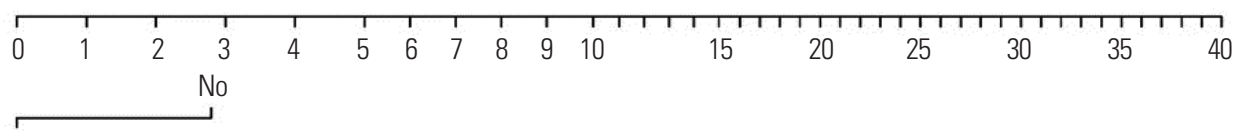

Yes

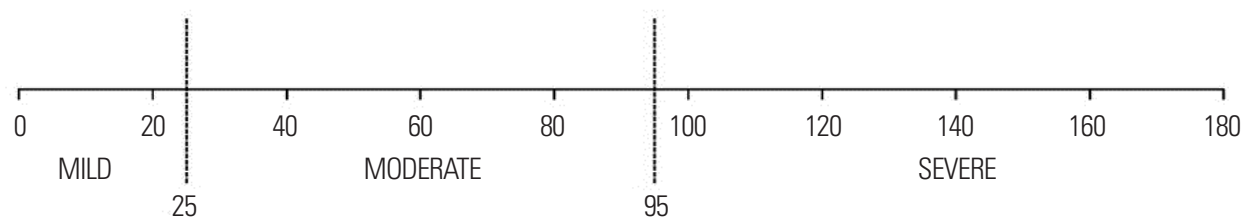

RYGB is suggested.

RYGB is recommended.

SG is suggested.

Recommendation
in average risk patients

Both procedures are highly effective.
Both procedures are less effective.

Figure 1. Nomogram for individualized metabolic surgery score. Preop, preoperative; HbA1c, glycosylated hemoglobin; RYGB, Roux-en-Y gastric bypass; SG, sleeve gastrectomy. Adapted from Aminian A, et al. Ann Surg 2017;266:650-7, with permission from Wolters Kluwer Health Inc. ${ }^{38}$ 
sulin use, duration of diabetes, and glycemic control ( $\mathrm{HbAlc}<7 \%)$ (Fig. 1). The user-friendly IMS score calculator is available online. ${ }^{39}$ Patients were categorized into three stages of diabetes severity according to the calculated IMS score and the probability of diabetes remission in each stage after RYGB and SG was provided. The authors went one step further, providing recommendations on the procedure of choice (RYGB or SG) for each severity stage based on the efficacy and risk-benefit ratio of each procedure. RYGB was suggested for those with mild disease (IMS score $\leq 25$ ) and moderate disease (IMS score 25-95), and SG for severe disease (IMS score $>95$ ). The prediction model was externally validated in an independent cohort of 241 patients.

\section{CONCLUSION}

Traditionally, diabetes care has been led by endocrinologists and the relevant medical team, particularly in Korea. As the era of metabolic surgery has begun, surgeons are more likely to be involved in diabetes treatment by providing an active effort to achieve glycemic control with surgical measures.

Optimal outcome following metabolic surgery would be achieving diabetes remission without antidiabetic medication. However, not all diabetes patients achieve diabetes remission after surgery and patients recommended for surgery should be carefully selected to avoid those who may benefit least from surgical procedures.

Bariatric/metabolic surgery is a far better option in improving glucose homeostasis, along with remarkable and sustained weight loss in morbidly obese patients with T2DM. However, the inconsistent results from different studies with the lower BMI population suggests that BMI criterion alone does not adequately predict the probability of diabetes remission in nonmorbidly obese patients undergoing metabolic surgery. Although several randomized controlled studies unanimously advocated metabolic surgery over conventional management, even in patients with $\mathrm{BMI}<35 \mathrm{~kg} / \mathrm{m}^{2}$, the debate over the antidiabetic effect of surgery is attenuated in the lower BMI population is still ongoing. In general, patients seeking surgery for the primary purpose of diabetes treatment would be older, have a lower BMI, and have poorer glycemic control, and the pathophysiology of diabetes may be different in these patients from the beginning. Understanding these potential differences would further facilitate the process in identifying more robust parameters relevant to diabetes and consequently to select patients best-suited for metabolic surgery in clinical practice. It is particularly more important in Asia where people are more vulnerable to T2DM, even with relatively low BMI compared to Caucasians.

An ideal prediction model for diabetes remission after metabolic surgery will guide clinicians and patients to make the optimal decision for diabetes treatment by balancing surgical risks against potential benefits. It should be able to select suitable candidates for metabolic surgery among those with diabetes and should be consistently reproducible in patients with different baseline characteristics. Thus far, the three prediction models (DiaRem, ABCD, and IMS scores) mentioned are the only models that have been externally validated in a relatively large independent population and are easy-to-use intuitive scoring systems, which assess the possibility of diabetes remission based on baseline patient characteristics. However, there was a considerable difference in the geographic origin of the derivation cohorts (DiaRem and IMS scores were from the United States and ABCD score was from the Asian population), as well as in the baseline characteristics of the patients (particularly of baseline BMI) between the scoring systems. Lee and colleagues ${ }^{40,41}$ compared $\mathrm{ABCD}$ and DiaRem scores, and subsequently with IMS score using data from Taiwanese patients. They suggested that $\mathrm{ABCD}$ score is better at predicting T2DM remission after metabolic surgery than both DiaRem and IMS scores. DiaRem and $A B C D$ scores were also tested in the Korean patient who underwent RYGB. ${ }^{42}$ Although the overall trend in both scoring systems correlated to actual diabetes remission rates, $\mathrm{ABCD}$ score appeared discriminate more in Korean patients. The ABCD score may be superior in predicting diabetes remission or improvement after surgery in the Asian population with a relatively lower BMI. These prediction models with their scoring systems should be further validated in various ethnicities to ensure universal applicability before implementation into clinical practice.

The second Diabetes Surgery Summit made an official announcement that metabolic surgery is recommended as a standard option for T2DM treatment ${ }^{10}$; therefore, more studies are focusing on therapeutic effects of metabolic surgery in terms of complete cure, i.e., "remission," of this complex chronic disease, which was believed to inevitably worsen over time. Nonetheless, one thing to 
be cautious about is that remission of diabetes should not be considered as the only goal of metabolic surgery. Most investigators agree that surgical outcome of metabolic surgery with the primary intent to treat T2DM should be considered in the continuum of improving glucose homeostasis and failure to achieve complete diabetes remission should not be considered a failure of surgical treatment. The majority of patients can still benefit from improved glycemic control after metabolic surgery although the degree of benefit may not be enough to satisfy the criteria of remission. Remission of diabetes, based on the current definition, although desirable, should not be regarded as the only goal of metabolic surgery or the only measure of success. Therefore, establishing a universally accepted goal and definition of successful treatment from metabolic surgery is necessary in the larger context of diabetes care to facilitate judicious patient selection for surgery.

\section{CONFLICTS OF INTEREST}

The author declares no conflict of interest.

\section{REFERENCES}

1. Ogurtsova K, da Rocha Fernandes JD, Huang Y, Linnenkamp U, Guariguata L, Cho NH, et al. IDF diabetes atlas: global estimates for the prevalence of diabetes for 2015 and 2040. Diabetes Res Clin Pract 2017;128:40-50.

2. Yoon KH, Lee JH, Kim JW, Cho JH, Choi YH, Ko SH, et al. Epidemic obesity and type 2 diabetes in Asia. Lancet 2006; 368:1681-8.

3. Seo MH, Kim YH, Han K, Jung JH, Park YG, Lee SS, et al. Prevalence of obesity and incidence of obesity-related comorbidities in Koreans based on National Health Insurance Service Health Checkup Data 2006-2015. J Obes Metab Syndr 2018;27:46-52.

4. Ha KH, Kim DJ. Trends in the diabetes epidemic in Korea. Endocrinol Metab (Seoul) 2015;30:142-6.

5. Jeon JY, Kim DJ, Ko SH, Kwon HS, Lim S, Choi SH, et al. Current status of glycemic control of patients with diabetes in Korea: the fifth Korea National Health and Nutrition Examination Survey. Diabetes Metab J 2014;38:197-203.
6. Buchwald H, Estok R, Fahrbach K, Banel D, Jensen MD, Pories WJ, et al. Weight and type 2 diabetes after bariatric surgery: systematic review and meta-analysis. Am J Med 2009; 122:248-56.e5.

7. Scopinaro N, Adami GF, Bruzzi P, Cordera R. Prediction of diabetes remission at long term following biliopancreatic diversion. Obes Surg 2017;27:1705-8.

8. Mingrone G, Panunzi S, De Gaetano A, Guidone C, Iaconelli A, Nanni G, et al. Bariatric-metabolic surgery versus conventional medical treatment in obese patients with type 2 diabetes: 5 year follow-up of an open-label, single-centre, randomised controlled trial. Lancet 2015;386:964-73.

9. Sjöström L. Review of the key results from the Swedish Obese Subjects (SOS) trial: a prospective controlled intervention study of bariatric surgery. J Intern Med 2013;273:219-34.

10. Pories WJ, Swanson MS, MacDonald KG, Long SB, Morris PG, Brown BM, et al. Who would have thought it? An operation proves to be the most effective therapy for adult-onset diabetes mellitus. Ann Surg 1995;222:339-50.

11. Ikramuddin S, Korner J, Lee WJ, Connett JE, Inabnet WB, Billington CJ, et al. Roux-en-Y gastric bypass vs intensive medical management for the control of type 2 diabetes, hypertension, and hyperlipidemia: the Diabetes Surgery Study randomized clinical trial. JAMA 2013;309:2240-9.

12. Cummings DE, Arterburn DE, Westbrook EO, Kuzma JN, Stewart SD, Chan CP, et al. Gastric bypass surgery vs intensive lifestyle and medical intervention for type 2 diabetes: the CROSSROADS randomised controlled trial. Diabetologia 2016;59:945-53.

13. Schauer PR, Bhatt DL, Kirwan JP, Wolski K, Brethauer SA, Navaneethan SD, et al. Bariatric surgery versus intensive medical therapy for diabetes: 3-year outcomes. N Engl J Med 2014; 370:2002-13.

14. Rubino F, Nathan DM, Eckel RH, Schauer PR, Alberti KG, Zimmet PZ, et al. Metabolic surgery in the treatment algorithm for type 2 diabetes: a joint statement by International Diabetes Organizations. Diabetes Care 2016;39:861-77.

15. Batterham RL, Cummings DE. Mechanisms of diabetes improvement following bariatric/metabolic surgery. Diabetes Care 2016;39:893-901. 
16. Panunzi S, De Gaetano A, Carnicelli A, Mingrone G. Predictors of remission of diabetes mellitus in severely obese individuals undergoing bariatric surgery: do BMI or procedure choice matter? A meta-analysis. Ann Surg 2015;261:459-67.

17. Mas-Lorenzo A, Benaiges D, Flores-Le-Roux JA, Pedro-Botet J, Ramon JM, Parri A, et al. Impact of different criteria on type 2 diabetes remission rate after bariatric surgery. Obes Surg 2014; 24:1881-7.

18. Blackstone R, Bunt JC, Cortés MC, Sugerman HJ. Type 2 diabetes after gastric bypass: remission in five models using $\mathrm{HbAlc}$, fasting blood glucose, and medication status. Surg Obes Relat Dis 2012;8:548-55.

19. Buse JB, Caprio S, Cefalu WT, Ceriello A, Del Prato S, Inzucchi SE, et al. How do we define cure of diabetes? Diabetes Care 2009;32:2133-5.

20. Aarts EO, Janssen J, Janssen IM, Berends FJ, Telting D, de Boer H. Preoperative fasting plasma C-peptide level may help to predict diabetes outcome after gastric bypass surgery. Obes Surg 2013;23:867-73.

21. Bhasker AG, Remedios C, Batra P, Sood A, Shaikh S, Lakdawala M. Predictors of remission of T2DM and metabolic effects after laparoscopic Roux-en-Y gastric bypass in obese Indian diabetics-a 5-year study. Obes Surg 2015;25:1191-7.

22. Hamza N, Abbas MH, Darwish A, Shafeek Z, New J, Ammori BJ. Predictors of remission of type 2 diabetes mellitus after laparoscopic gastric banding and bypass. Surg Obes Relat Dis 2011;7:691-6.

23. Hayes MT, Hunt LA, Foo J, Tychinskaya Y, Stubbs RS. A model for predicting the resolution of type 2 diabetes in severely obese subjects following Roux-en Y gastric bypass surgery. Obes Surg 2011;21:910-6.

24. Park JY, Kim YJ. Prediction of diabetes remission in morbidly obese patients after Roux-en-Y gastric bypass. Obes Surg 2016; 26:749-56.

25. Sjöström L, Peltonen M, Jacobson P, Ahlin S, Andersson-Assarsson J, Anveden Å, et al. Association of bariatric surgery with long-term remission of type 2 diabetes and with microvascular and macrovascular complications. JAMA 2014;311: 2297-304.

26. Yska JP, van Roon EN, de Boer A, Leufkens HG, Wilffert B, de Heide LJ, et al. Remission of type 2 diabetes mellitus in patients after different types of bariatric surgery: a populationbased cohort study in the United Kingdom. JAMA Surg 2015; 150:1126-33.

27. Rao WS, Shan CX, Zhang W, Jiang DZ, Qiu M. A meta-analysis of short-term outcomes of patients with type 2 diabetes mellitus and $\mathrm{BMI} \leq 35 \mathrm{~kg} / \mathrm{m} 2$ undergoing Roux-en-Y gastric bypass. World J Surg 2015;39:223-30.

28. Baskota A, Li S, Dhakal N, Liu G, Tian H. Bariatric surgery for type 2 diabetes mellitus in patients with BMI $<30 \mathrm{~kg} / \mathrm{m} 2$ : a systematic review and meta-analysis. PLoS One 2015;10: e0132335.

29. Dixon JB, Hur KY, Lee WJ, Kim MJ, Chong K, Chen SC, et al. Gastric bypass in type 2 diabetes with BMI < 30: weight and weight loss have a major influence on outcomes. Diabet Med 2013;30:e127-34.

30. Yu H, Di J, Bao Y, Zhang P, Zhang L, Tu Y, et al. Visceral fat area as a new predictor of short-term diabetes remission after Roux-en-Y gastric bypass surgery in Chinese patients with a body mass index less than $35 \mathrm{~kg} / \mathrm{m} 2$. Surg Obes Relat Dis 2015;11:6-11.

31. Still CD, Wood GC, Benotti P, Petrick AT, Gabrielsen J, Strodel WE, et al. Preoperative prediction of type 2 diabetes remission after Roux-en-Y gastric bypass surgery: a retrospective cohort study. Lancet Diabetes Endocrinol 2014;2:38-45.

32. Mehaffey JH, Mullen MG, Mehaffey RL, Turrentine FE, Malin SK, Kirby JL, et al. Type 2 diabetes remission following gastric bypass: does diarem stand the test of time? Surg Endosc 2017;31:538-42.

33. Aron-Wisnewsky J, Sokolovska N, Liu Y, Comaneshter DS, Vinker S, Pecht T, et al. The advanced-DiaRem score improves prediction of diabetes remission 1 year post-Roux-en-Y gastric bypass. Diabetologia 2017;60:1892-902.

34. Lee WJ, Hur KY, Lakadawala M, Kasama K, Wong SK, Chen SC, et al. Predicting success of metabolic surgery: age, body mass index, C-peptide, and duration score. Surg Obes Relat Dis 2013;9:379-84.

35.Lee WJ, Almulaifi A, Chong K, Chen SC, Tsou JJ, Ser KH, et al. The effect and predictive score of gastric bypass and sleeve gastrectomy on type 2 diabetes mellitus patients with BMI 
$<30 \mathrm{~kg} / \mathrm{m}(2)$. Obes Surg 2015;25:1772-8.

36. Lee WJ, Almulaifi A. Recent advances in bariatric/metabolic surgery: appraisal of clinical evidence. J Biomed Res 2015;29: 98-104.

37. Lee WJ, Almulaifi A, Tsou JJ, Ser KH, Lee YC, Chen SC. Laparoscopic sleeve gastrectomy for type 2 diabetes mellitus: predicting the success by ABCD score. Surg Obes Relat Dis 2015; 11:991-6.

38. Aminian A, Brethauer SA, Andalib A, Nowacki AS, Jimenez A, Corcelles $\mathrm{R}$, et al. Individualized metabolic surgery score: procedure selection based on diabetes severity. Ann Surg 2017; 266:650-7.

39. Cleveland Clinic. Individualized metabolic surgery score [Internet]. Cleveland, OH: Cleveland Clinic Lerner Research In- stitute; 2018 [cited 2018 Dec 14]. Available from: http://riskcalc. org/Metabolic_Surgery_Score/

40. Lee WJ, Chong K, Chen SC, Zachariah J, Ser KH, Lee YC, et al. Preoperative prediction of type 2 diabetes remission after gastric bypass surgery: a comparison of DiaRem scores and ABCD scores. Obes Surg 2016;26:2418-24.

41. Chen JC, Hsu NY, Lee WJ, Chen SC, Ser KH, Lee YC. Prediction of type 2 diabetes remission after metabolic surgery: a comparison of the individualized metabolic surgery score and the ABCD score. Surg Obes Relat Dis 2018;14:640-5.

42. Park JY, Kim YJ. Reply to the comment on: "prediction of diabetes remission in morbidly obese patients after Roux-en-Y gastric bypass". Obes Surg 2016;26:3011-3. 